Таким образом, анатомия и живопись давно идут рука об руку, ведь оба предмета являются своего рода искусством: первое - искусство изучения внутреннего строения тела человека, второе - искусство его отображения на полотнах, гравюрах и рисунках. Произведения живописи позволяют изучить человека как снаружи, так и изнутри, предоставляя возможность углубиться в изучение анатомии через картины художников. Они усиливают эмоциональное восприятие учебного материала, активируют процесс запоминания через принцип наглядности, вызывают эстетическую реакцию, создают определенное настроение. Интеграция курсов биологии и мировой художественной культуры может быть осуществлена на многих уроках и на этапе введения нового материала, и на этапе закрепления. Для этого можно использовать анатомические рисунки и картины известных художников.

$$
* * *
$$

1. Строев Юрий Иванович, Чурилов Леонид Павлович, Шмелев Алексей Алексеевич Медицина и изобразительное искусство // Пространство и Время. 2014. №3 (17). URL: https://cyberleninka.ru/article/n/meditsina-i-izobrazitelnoe-iskusstvo

2. Теремов А.В. Интегративные тенденции в естественнонаучном и гуманитарном образовании школьников. Монография. - М.: Прометей, 2007.

3. Медицинская анатомическая иллюстрация - история изучения тела человека в атласах 5 столетий. URL: https://habr.com/ru/company/visual-science/blog/233787/

4. Федеральный государственный образовательный стандарт основного общего образования (утверждён приказом Министра образования и науки РФ от 17 декабря 2010 г. № 1897

\title{
Шанин А.В. \\ Новый взгляд на эмоциональное состояние, психику, психологию и физиологию ощущений. Техника «Паруса»
}

(Россия, Москва)

doi 10.18411/gq-31-03-2021-41

idsp sciencerussia-31-03-2021-41

\section{Аннотация}

В данной статье описывается авторская техника дыхания «Паруса», которая позволяет добиться изменения эмоционального состояния «непосредственно», без помощи внешних стимулов. Приведен краткий экскурс по этапам открытия данной методологии самим автором, а также по ее тестированию и практическому применению.

Ключевые слова: техника «Парус», дыхание, глубокий вдох, дофамин, дофаминовый клапан, коучинг.

Старт данного исследования состоялся примерно в 2012 году. А началось оно со статьи про нос, в которой подробно расписан процесс осознания носа как глаз, и использование его как навигатора в жизненных ситуациях. Запускался вопрос: «Кого бы вы понюхали, как себя?»

Была собрана исследовательская группа и проведена серия экспериментов, в которых были выявлены несколько физиологических особенностей. Благодаря этим особенностям, появилась техника, о которой я расскажу чуть ниже.

Я, Шанин Александр, популярный российский бизнес-коуч, один из лидеров рынка коуч-индустрии, помогающий гражданам Российской Федерации выйти на новый уровень доходов и найти свой уникальный способ зарабатывать деньги. Также, ведущий специалист в области НЛП-коучинга, генеративной психологии, работы с подсознанием и изменения способов мышления.

Постоянно повышаю свою квалификацию и прохожу обучение у легендарных бизнес тренеров, звезд коучинга, ведущих американских, европейских психологов, 
психотерапевтов и тренеров по личностному росту, входящих в ТОП-100 самых влиятельных экспертов в области психотехнологий, в их числе: Фрэнк Пьюселик, Роберт Дилтс, Брайан Трейси и другие.

Имею награды и сертификаты международного образца.

Ранее работал на государственной службе и помогал первым лицам разобраться с внутренними противоречиями, связанными с непростыми решениями.

До сих пор являюсь госпредставителем и советником в спорных и затруднительных ситуациях.

Также работал с ветеранами боевых действий в рамках реабилитации ПТСР.

Занимался реабилитацией наркозависимых совместно с Фрэнком Пьюсиликом, разработчиком НЛП.

Являюсь наследником научной исследовательской базы родителей, чьи учебники по психологии внесены в золотой фонд российской науки.

Более 15 лет изучаю, исследую и создаю различные психотехнологии. $500.000 \$$

Инвестиции в личное образование на сегодняшний момент составили более

Мои технологии напрямую связаны с программами управления государством.

Совокупный доход моих клиентов более 300.000.000 рублей. области.

Именно работа с зависимыми натолкнула меня на исследования в данной

Некоторое время назад я пришел к выводу, что все наши действия сведены к получению эмоций.

Любое начинание по итогу сводится к ощущениям, ради которых мы это затеяли.

Влияние на собственное состояние чаще всего лежит через любые покупки, стремление к роскоши, секс и употребление различного рода препаратов: наркотики, алкоголь.

Фактически, такая позиция означает, что между нашим эмоциональным состоянием есть посредник, который воздействует на него с помощью различных действий, приносящих удовольствие.

Идеологией моего исследования стала мысль и вопрос:

Зачем мне, человеку, который чувствует, нужны посредники между ощущениями?

И что мне нужно сделать, чтобы чувствовать то же самое, что я чувствую от покупок или влияния извне, но самостоятельно, без посредников?

Кульминацией моего исследования стала полугодовая изоляция и различные практики воздержания.

Я молчал почти 6 месяцев, проводил сухое голодание длительностью 3 дня с периодичностью 2 раза в месяц, на протяжении всего периода эксперимента.

Наблюдая свое эмоциональное состояние и отслеживая его изменения на протяжении всего периода исследования.

В один из дней я заметил, что влияет на мое настроение и что его создает.

Это был глубокий вдох.

А именно верхушка вдоха.

При достижении которого наступает облегчение, и на некоторое время, настроение переходит в приподнятое состояние.

Но, после приподнятого состояния, случается откат и настроение меняется на нисходящее, до следующего глубокого вдоха.

Некоторое время я исследовал этот факт и наблюдал выход в точку облегчения, ту самую верхушку вдоха. 
У меня появилось ощущение, что на пике вдоха я как будто дотягиваюсь до какой-то кнопки, и в легких открывается клапан который «впрыскивает» что-то в легкие, после чего наступает мгновенное облегчение.

Моя гипотеза данного феномена базируется на знаниях, полученных в рамках программы факультета лабораторной диагностики медицинского колледжа №1 при Г.К.Б. им С.П. Боткина.

Понимание физиологии человека, полученное за годы обучения, наталкивает меня на мысль о том, что на верхушке вдоха в организм человека происходит «впрыск» дофамина.

Так как данный способ максимально эффективно и быстро способен обогатить кровеносную систему, доставляя дофамин в клетки всего тела вместе с кислородом.

Поэтому я считаю, что на верхушке вдоха в легкие впрыскивается дофамин, и именно этот впрыск мы считаем удовлетворительным глубоким вдохом.

Приняв эту вводную как факт и отследив спад настроения между глубокими вдохами, я решил понаблюдать, как можно воздействовать на этот «впрыск».

Сначала я пытался сделать его чаще, но заметил, что, как только я беру этот процесс под контроль, клапан, который отвечает за впрыск как будто спазмируется и вообще перестает открываться.

Меня охватил страх, и случилась сильная паническая атака.

Я пытался вдохнуть, но не мог. Облегчения не было. Вдох был не достаточно глубокий, как мне казалось.

Мое состояние усиливало осознание полной изоляции, и молчание вот уже как несколько месяцев, помощи ждать было неоткуда.

Мне удалось себя успокоить и взять состояние под контроль.

Как следствие, я заметил, что за время панической атаки и моих тщетных попыток сделать вдох с выходом в точку облегчения и открыть дофаминовый клапан, процесс дыхания продолжался и фактических причин для паники не было.

Как только мне удалось себя успокоить, и спазм клапана прошел, мне удалось вдохнуть.

И это был самый вкусный вдох в моей жизни.

Я почувствовал максимальное предоргазменное состояние, ощущение достатка, счастья, полного комфорта и удовлетворенностью жизнью.

Этот фрагмент моего исследования считаю максимально важным, так как с этого момента я понял, что впрыскиваемое вещество можно накапливать.

После 20 минутного воздержания, от выхода в точку удовольствия случается совсем другой по ощущениям вдох. Более насыщенный и богатый.

Это очень трудно передать словами.

С этого момента мое исследование подстегнул азарт и я начал думать, что будет, если копить весь день и потом вдохнуть.

На первых стадиях мне не удавалось пройти дальше, чем 5-7 вдохов, и копить больше 1 часа. Случались панические атака и ощущение близкой смерти от нехватки кислорода.

Я вспомнил, как наблюдал наркозависимых и их ломки, когда занимался реабилитацией наркозависимых совместно с разработчиком НЛП Фрэнком Пьюсиликом.

Казалось, что испытываю нечто похожее.

В тот момент мне помогло вдыхать через нос в полные легкие, но не дотягиваться до верха. Со словами самому себе: «видишь, легкие полны кислородом, а то, что сверху, давай копить».

Череда попыток и самоуспокоения, и мне удалось победить паническую атаку и весь этот процесс взять под контроль. 
Позже я заметил, что всю жизнь, когда случался такой глубокий вдох, я как бы его помнил, мое внимание его отслеживало.

Через два дня после моего решения копить, клапан или мышечная система клапана окрепла, и я смог перевести процесс на другой, новый уровень.

Мои ощущения начали меняться.

Тот ком в горле, который я чувствовал в начале практики, превратился в приятные ощущения в области груди, которые как будто наполнялись с каждым вдохом.

Я глубоко вдыхал, а верхушку оставлял нетронутой, откладывая на потом.

По аналогии с накоплением капитала, - живи на дивиденды.

Это был переломный момент моего полугодового исследования, и через месяц после практик я почувствовал, как разительно изменилось мое эмоциональное состояние.

Мне стало хорошо и комфортно, настроение улучшилось, я просыпался радостный как ребенок и с каждым новым вдохом чувствовал, как мне хорошо и становится только лучше.

Я почувствовал, что у меня расправилось что-то в области легких и по ощущениям это были «паруса, наполненные ветром хорошего настроения».

Структура вдоха изменилась, для того, чтобы испытать то самое ощущение, которое раньше могло случиться только на пике вдоха, достаточно было сделать часть обычного вдоха.

Ощущение сместилось до середины вдоха, и появилась возможность управлять клапаном самостоятельно. То есть, просто открывать его по желанию.

После испытаний методики на себе, я поделился открытием с исследовательской группой, которая получила схожие результаты.

Мы отследили, как изменился способ думать. Мозг начал совсем по-другому работать и принимать решения. Начали появляться идеи, которых раньше не было в голове.

Началась череда открытий.

По моим ощущениям, вещество, которое накапливается, способствует запуску темных областей сознания, открывая новые возможности мировоззрения и взглядов на окружающий мир. Как в фильме «Области тьмы», только без препаратов.

Что самое важное, большую часть времени ощущения можно сравнить с предвкушением дорогой покупки или свидания с гарантированной близостью.

Условно, можно назвать это устойчивым предоргазменно-эйфорийноприподнятым состоянием. То чувство, когда переполняет хорошее настроение, и ты знаешь, откуда оно берется.

Стрессоустойчивость.

Мы заметили прирост стрессоустойчивости.

Наработалась технология нахождения в конфликтных ситуациях.

Мы заметили, что если у одного человека в коллективе раздраженное состояние, то это состояние передается всем участникам диалога. Но как?

Именно в момент глубокого вдоха.

То есть достаточно выйти в верхнюю точку дыхания в момент конфликта и моментально наполняешься раздражением или состоянием оппонента.

И, наоборот, если в момент конфликта воздерживаться от выхода в верхнюю точку вдоха, и удерживать клапан закрытым, то эмоциональное состояние не меняется и остается устойчивым и комфортным. Как будто тебя это не касается.

А оппонент через некоторое время успокаивается, так как не встречает сопротивления на своем пути и ему фактически нечего защищать. 
После успешного прохождения испытаний на нашей исследовательской группе, в которой мы получили $100 \%$ результат, я начал применять технику в своей коучинговой программе по увеличению дохода.

Все, кто освоил технику, увеличили свой доход, и нашли уникальные идеи для решения своих финансовых ситуаций. И снова $100 \%$ результат.

После чего, на время пандемии COVID-19 все те, кто владел данной дыхательной техникой, переносили заболевание в легкой форме без осложнений и госпитализации.

COVID, воздействуя на нервную систему и на легкие, ограничивает возможность дотянуться до верхушки дыхания, от чего у человека начинается паника и он начинает усиленно пытаться вдохнуть, давая повышенную нагрузку на легкие.

В свою очередь, усиленное дыхание и паника приводит к гипервентиляции и отеку.

В случае с теми, кто владел техникой на момент заболевания, им не требовалось давать высокую нагрузку на легкие, так как они могли получить пик облегчения на более низкой фазе вдоха, сохраняя спокойное дыхание.

С момента открытия данного феномена и по сей день, этот способ дыхания с воздержанием от точки пика, принес массу открытий и осознаний, огромное количество идей, которые принесли моим клиентам миллионы.

Сегодня я хочу поделиться открытием со всем миром и посмотреть, как изменится мир под влиянием всеобщего ощущения счастья, любви, гармонии и хорошего настроения.

Встречайте, техника «Паруса», технология выполнения:

Внимание!

Этап номер один:

Отследить глубокий вдох.

Этап номер два:

Сделать вторичный глубокий вдох, сразу после первого.

Этап номер три:

Отследить разницу между вдохами. Отследить более насыщенный вдох.

Итого мы имеем два различных глубоких вдоха. В одном из вдохов мы как бы «дотягиваемся до верхушки» и приходим в точку удовольствия - это более насыщенный вдох. В другом вдохе этого не происходит, он менее насыщенный.

Как только мы отследили вдох, в котором мы «дотягиваемся до верхушки» и вышли в точку удовольствия, мы осознанно начинаем отказываться от того, чтобы дотянуться до этой «верхушки» или иными словами, прерывать вдох до достижения точки удовольствия.

Мы как бы откладываем «дотянуться до верхушки» и перейти в точку удовольствия на другой раз, час, день, месяц, год.

Задача полностью отказаться от «дотягиваться до верхушки» или, иными словами, полный отказ от выхода в точку удовольствия на постоянной основе, отслеживая ежедневные изменения в эмоциональном состоянии.

Первым делом может показаться, что вы задыхаетесь. Оно и понятно, вы все эти годы выходили в точку удовольствия, не обращая на это внимания, и сильно зависите от этого. А у зависимостей есть цена.

Всегда можно вдохнуть через нос, не дотягиваясь до верха, и сказать самому себе, что легкие полные и никакого кислородного голодания нет.

Если вам удастся перейти на новый режим дыхания, то через два дня вы увидите перемены в своем настроении. Оно будет набирать обороты с каждым днем, с каждым последующим вдохом, в котором вы воздержались.

Но у всего есть цена и цена этой техники, - тот страх, через который вам предстоит пройти. Страх самого себя. 
Польза методики дыхания:

Через некоторое время ваше эмоциональное состояние станет более ярким, комфортным и приятным. Вы почувствуете, как в груди расправляются ваши паруса, и жизнь начинает меняться в лучшую сторону.

Вы почувствуете, как будто жизнь подхватила вас, и ваши «паруса» наполнены ветром хорошего настроения и приятных ощущений.

Именно эта техника уже несколько лет подряд помогает мне пребывать в состоянии эмоционального подъема и генерировать те идеи, которые помогают моим клиентам зарабатывать миллионы.

Я хочу, чтобы нас было больше, чтобы мы своими светлыми идеями и настроением делали мир лучше, а наше финансовое положение стабильнее.

И, пусть в новом и во всех последующих годах ваша жизнь будет под полными парусами.

\section{Assanova D., Knol M.}

Interlanguage interference in the acquisition of foreign language pronunciation

Buketov university of Karaganda (Kazakhstan, Karaganda)

doi 10.18411/gq-31-03-2021-42

idsp sciencerussia-31-03-2021-42

\section{Abstract}

When considering interference from a psycholinguistic point of view, it becomes obvious that the speech flow is automatically divided into bundles of differential features that are identical to the elements of the native language. Signs of phonemes that are irrelevant from the point of view of the phonological system of the native language, but differentially significant from the point of view of the foreign language, are discarded, and, conversely, signs that are absolutely insignificant for a non-native language are the main ones in the perception and reproduction of speech in a foreign language. Thus, it turns out that a native speaker of any language turns any unfamiliar sound (or any sound sequence) into a sequence of phonemes of the native language, resulting in an incorrect phonological interpretation. The properties of a bilingual, which are determined by the phonological hearing that exists in his linguistic consciousness, can be considered the most general explanation of the phenomenon of interference itself. Teachers and methodologists pay considerable attention to this phenomenon primarily because the process of superimposing the systems of the native language on the system of the non-native (or interference) generates an accent in the speech of a bilingual native speaker, which is like a kind of mirror, where the signs of the native language are reflected. If the accent is a system of stable skills of incorrect speaking, then the mistakes in pronunciation that inevitably occur in the speech of a bilingual when learning a folk language are random, but they are often difficult to correct. In order to quickly correct them, teachers should know the reasons for their occurrence.

Keywords: Interlanguage interference, foreign language, native language, phonological system, reproduction of speech, phonemes, phonological interpretation.

Many scientists and researchers pay considerable attention to the problems of bilingualism, namely, the interfering influence of the native language when mastering a foreign language.

When considering interference from a psycholinguistic point of view, it becomes obvious that the speech flow is automatically divided into bundles of differential features identical to the elements of the native language. Phonemic features that are irrelevant from the point of view of the phonological system of the native language, but differentially significant from the point of view of the foreign language, are discarded, and, conversely, features that 